\title{
Organizational functioning in Turkish higher education system: Birnbaum's five models of institutional governance
}

\author{
Hatice Ergin Kocatürk ${ }^{1}$ and Engin Karadağ ${ }^{2}$ \\ ${ }^{1}$ Istanbul University-Cerrahpaşa, Turkey (ORCID: 0000-0001-7639-9853) \\ 2Akdeniz University, Turkey (ORCID: 0000-0002-9723-3833)
}

\begin{abstract}
Expectations from higher education institutions and systems are constantly increasing at both national and global levels. In addition to the variety of services provided by higher education institutions, the rise in expectations makes management of these institutions more difficult. However, while formations such as mission differentiation, thematic university structure, and regional development universities differentiate the objectives of higher education institutions from each other, attempts to achieve these specific objectives may bring along an organizational and informal structure specific to the institution. Based on this premise, the aim of this study is to examine the institution-specific governance models observed in Turkish higher education institutions. This case study is based on the five models of organizational functioning introduced by Birnbaum with the perspective of new institutionalism. The data of the study were obtained from two sources: Existing literature and interviews with 10 academics from higher education institutions. Accordingly, the governance models frequently observed in Turkish higher education institutions are bureaucratic model, political model and organized anarchy. In addition, the rapid increase in the number of higher education institutions and the dependence on resources increase the homogeneity between higher education institutions.
\end{abstract}

Keywords: Turkish higher education system; Birnbaum's five models of governance; Governance in higher education; Organizational functioning in higher education; New institutionalism

Article History: Submitted 30 June 2021; Revised 17 November 2021; Published online 31 December 2021

\section{Introduction}

The scope and number of studies in the field of higher education is constantly increasing. In addition to the economic benefits of transforming into an information society, social equality and mobility and ensuring social cohesion are of critical importance for individuals on both national and global scales. Moreover, higher education currently provides an institutional basis for all academic disciplines (Brennan \& Teichler, 2008). Examination of higher education and higher education governance includes many organizational and structural factors. The rapid increase in the number of expectations and beneficiaries from higher education and the transition to the information society necessitated an original and autonomous functioning in higher education

Address of Corresponding Author

Hatice Ergin Kocatürk, PhD, İstanbul University-Cerrahpaşa, Hasan Ali Yücel Faculty of Education, 34500 Büyükçekmece/İstanbul, Turkey.

$\triangle$ hatice.ergin@iuc.edu.tr

How to cite: Ergin Kocatürk, H. \& Karadağ, E. (2021). Organizational functioning in Turkish higher education system: Birnbaum's five models of institutional governance. Journal of Pedagogical Research, 5(4), 230-250. https:/ /doi.org/10.33902/JPR.2021474637 
systems and institutions, and the traditional management phenomenon has left its place to governance over time. While the concept of management is generally considered as a deliberate systemic organization in the triangle of politics, economy and society, governance emphasizes the functioning at the organizational level and the uniqueness of organizations (Capano, 2011). In other words, governance can be considered as the reflection of system-level management on higher education institutions. Becher and Kogan (1992), on the other hand, argue that governance focuses on the process and structure. Although the concepts of administration or management have been used frequently until recently, the frequency of use of the concept of governance has increased considerably in recent studies in the field of higher education (Zgaga, 2006).

According to organizational studies, formal organizations are formed by the appropriate organization of human and other resources to achieve predetermined goals. However, it cannot be said that universities or higher education institutions have definite boundaries or a single purpose. Teaching, research, service to the community, finding solutions to social problems and management of scientific facilities are the foremost of these purposes. These could be considered as reflections of how these institutions are defined. In other words, universities can be considered as organizational designs for the production of predetermined or desired outputs. Higher education institutions, which differ from other educational organizations in many aspects such as product, process, technology, skills, and relations, have some characteristic features, especially structural features and decision-making processes, and their "complexity" comes first (Baldridge et al., 1974). Universities with their many faculties, institutes, colleges, research centers and administrative units are managed with the coordination of this orderly and specific complexity. The management of educational institutions is different from the management of other institutions, and strict order or bureaucracy is not possible in educational institutions and unforeseen situations will require going out of the standards (Weick, 1976).

The constantly changing structure of universities causes rapid paradigmatic transformations in the field of higher education management. Just like in educational administration, modern approaches of organizational science are insufficient in the analysis of multidimensional/multiproduct organizations and lead researchers to approach the process from different perspectives. Aypay (2001) states that bureaucratic-structuralist approaches based on the concepts of hierarchy, authority, rationality and functionalist theories based on informal structure, change, conflicts of interest are insufficient in organizational analysis, and that the perspective of "new institutionalism" interacts with sciences such as sociology, economics, and politics. It represents an interdisciplinary perspective. However, while the interdependence of organizations with their environment transforms organizations into a variable and permeable structure, environmental pressures in the functioning of organizations, in other words "institutional environment", have begun to be recognized (Scott, 1981). Resource dependency and institutional legitimacy are the basics of relations with the environment (Meyer \& Rowan, 1977). Among the benefits of the institutional environment are institutionalization, other environments that regulate each other, environmental rules and norms, myths and irrational actions. Accordingly, organizations unconditionally accept myths or beliefs in their institutional environment in order to maintain their existence, and for educational organizations, these myths include programs, policies, services, methods and similar processes. It is also possible to rationalize myths that are already accepted unconditionally; professions, technologies, awards and certification can be given as examples of this (Scott, 2001). DiMaggio and Powell (1983), stating that other organizations may accept existing environments and myths unquestioningly, argue that over time, all organizations resemble each other (institutional isomorphism) and thus try to ensure legitimacy. This can also be expressed as organizations adopting the already tried and accepted ones as "social behavior" rather than determining a new environment or trying to compose one (Meyer \& Rowan, 2006).

The five models developed by Birnbaum (1988) provide a useful framework for examining and analyzing the functioning and governance in higher education institutions, considering the characteristics such as the establishment, age, size, location, type and degree of the programs 
offered. The models listed as professional, bureaucratic, political, organized anarchy and cybernetic contain certain organizational behavior patterns and highlight the uniqueness of the functioning and governance of higher education institutions.

\subsection{Collegial Model}

Collegial model grounds on consensus, power sharing, common goals and expectations, consultation-based leadership and undertaking responsibilities collectively. The status difference between stakeholders is often ignored and stakeholders or colleagues see their institutions as a collegium. In this model, hierarchy is that important; interaction between members or stakeholders is usually informal. The model, which envisages an egalitarian and democratic structure, all members, including students and administrative staff, have the right to speak when necessary. Collegiality, which is based on consensus, more experienced ones or the staffs who are more effective thanks to their position can be efficient when making decisions. Kerr (1982) states that there is also a tendency towards consensus in research universities and those more experienced members of academic groups are effective in decision making. The main task of the administrators is to provide support and represent the university. Within the professional collegium structure, administrators are also seen as their subordinates and are actually responsible for implementing the decisions of this professional collegium. The administrators selected from among the academics serve for a certain period of time and return to their duties when their term of office expires. In these institutions, which have values such as the adoption of common goals, commitment to the collective structure and agreement on organizational identity, communication with graduates is maintained in order to ensure the continuation of a strong and consistent culture or structure consisting of symbols, ceremonies and myths, and graduates usually take part in highlevel committees.

\subsection{Bureaucratic Model}

As the structure of organizations expands, the number of units increases and their work becomes more specialized. The management of these organizations becomes difficult and the operability of their unwritten norms decreases (Blau, 1994). While this requires written and structured interaction tools, it also bureaucratizes the organization (Stroup, 1966). Birnbaum (1988) argues that bureaucratic structures are in relationship with organizational programs to achieve certain goals of the organization, and as the behavior becomes standardized, the actions and processes of organizations become more predictable and thus organizations become more effective and productive. In this model, job descriptions, rules and regulations have a very important place. Individuals communicate with each other through job descriptions and roles. Rules are also the only way to solve problems and it is important that all staff learn and communicate these solutions. This situation causes the staff to approach all problems as if they were the same and they do not to seek new or original solutions. However, rules can be treated as organizational memory and are tools for change. Rules are also a protective tool for employees so that they can turn their managers down in situations that exceed their responsibilities or are prone to abuse. When the rules are applied equally to everyone, problematic situations such as bias or favor will be eliminated. Bureaucratic organizations are also rational organizations. The decisions they make may not always be the best, but they always have a basis. Allison (1971) states that rationality is making consistent choices within certain constraints. Rationality requires that goals be clearly defined. Rationality and a concrete structure create and maintain the culture of the institution.

Bureaucratic leaders rely on clearly articulated organizational charts to define division of labor and routinely communicate through written documents rather than face-to-face. Bureaucratic leaders are defined as managers who act as rational analysts, setting and achieving a clearly defined set of goals and objectives. Another source of leadership is appointments based on rationality. Employees' belief in the competence and experience of their superiors will also affect their performance. One source of the power of bureaucratic leaders is the analytical approach they display in their decision-making processes. 


\subsection{Political Model}

In large-scale organizations, there may be many subgroups. These groups may be united by academic, ethnic, or ideological similarities, but these subgroups do not come together to form a whole or a common focus of power. Rather, it provides decentralization of authority or decisionmaking and only takes control of a group of managers. When we look at the system in general, we come across a complex structure consisting of many powerful and authoritarian sub-groups, each in its own context. In this case, since the expectations and goals of the subgroups will be very different from each other, bargaining and negotiation on impact and resource use becomes inevitable. In this context, political organizations can be considered as the sum of sub-coalitions with different interests, preferences and goals. Subgroups need to gain, develop and use power in order to dominate or achieve their desires. In these organizations where authority or chain of command cannot be applied, it is often not possible to reach an agreement even on the goals or how to achieve the goals, and in cases where a decision cannot be made, the only structure that stakeholders can rely on is politics.

It can be said that political leaders act on the basis of informal information rather than available data. In this model, there are no clear or standard rules even though the roles and duties are certain and limited, and the university governance takes place on an intuitive, irrational precedent and an unplanned environment. Organized anarchy could be mentioned because each individual does what he wants when he wants. Coordination or control is not applied, and resources are used as processes or situations arise. Decisions are outcomes produced by the system but not intended by anyone and not strictly controlled by anyone (Cohen \& March, 1974).

\subsection{Organized Anarchy Model}

Organized anarchies have three key features; problematic goals, uncertain technology, and fluid participation. Unclear goals do not give an idea about how the technology will be used while uncertainty of the decision-making processes does not give an idea about the organizational structure. Organizations do not plan their goals or preferences, but discover through trial and error. Since there is no research on which technology is more efficient, the use of technology takes place through trial and error, previous experiences, imitation, and discovery when necessary. It is not possible to talk about continuous participation as individuals only take responsibility for the issues they are interested in (Cohen \& March, 1974).

There are certain rational stages of decision making in organizations. However, in a complex environment or organization, there may be too many variables or factors to follow these stages. The anarchy model may also emphasize this situation, suggesting that possible shortcomings in the communication cycle cause loose coupling, and in fact, this may cause the two related situations to be unrelated. In other words, when organizational elements are loosely connected, what happens is not immediately known, why it happens is hidden, and it is unclear whether it is good or not (March \& Olsen, 1989). In these loose connections, there is a flow, not a rigid order, but it is there even if it is not seen. Garbage can approach is utilized when making decisions in the anarchy model. Accordingly, the choice opportunities compose the garbage can; problems, solutions, and participants are the streams of the garbage can. In the garbage can, specific problems, participants and solutions form a special selection point and are tightly coupled. The decisions made cut the close connection between them with the point of choice. If the same decision was made in a different time period or if a different decision was made in the same time period, the problems, solutions and participants in the garbage can exhibit different degrees of cohesion. So, it is very difficult to make decisions in these organizations, to use previous decisions as a precedent or to predict the consequences of the decision (Birnbaum, 1988). In summary, it is defined as a loosely coupled, non-linear, open system that routinely confronts with problematic goals, an undefinite technology and the fluid participation of members in the decision-making process. The role of the anarchic leader is to understand the meaning of events and the culture of the organization and to offer alternative solutions to problems. 


\subsection{Cybernetic Model}

Looking at some higher education institutions from afar, it can be observed that they are in complete disorder and even chaos. Despite this, these organizations fulfill their duties or what is expected from them. What is not seen at first glance in these organizations is that there is an order in the chaos. Although the question of who created or maintained this order brings to mind managers first, these organizations were actually complete in the absence of the manager. Birnbaum (1988) states that this order is realized by cybernetic control. Cybernetics evolved from the Greek words "kybernaein" meaning to steer a ship, and "kybernetike" meaning the art of doing this. Today, it is considered in the broadest sense as the theory of control and communication in machines and organisms (Zgaga, 2006). When both ancient and modern meanings are considered together, the phenomenon of "control" or "direction" draws attention. It is assumed that its influence in organizational and management sciences started with the "General System Theory" developed by Ludwig von Bertalanffy (Vallée, 2003).

The cybernetic model is described as an open system that uses self-correcting mechanisms or thermostats to monitor activities. It is quite similar to a thermostat which runs to keep the temperature at the desired level and activates when the temperature drops, and then turns off when the temperature reaches at the desired level. There is a success acceptance interval in cybernetic systems. If the achieved success is not at the expected level of success, necessary attempts are made to reach the expected level.

Since cybernetic organizations tend to manage themselves, there is usually no need for a rational manager. The task of managers in these organizations is to respond to ordinary or unusual disruptions rather than to manage or change them. These situations, in which the power of the organization exceeds the leader, indicate that cybernetic principles work. Cybernetic leaders must be able to keep an eye on organizational changes and establish a mechanism for communication through feedback loops by deploying teams or monitors to subsystems across an organization. The focus of the cybernetic model of organizational functioning is to maintain balance in an organization when multiple models of leadership and organization are present. This is accomplished through cybernetic controls-that is, self-correcting mechanisms that monitor organizational functions and provide participants with attention cues or negative feedback when things are not going well. Negative feedback systems detect and correct errors, so when something that moves the organization in an undesirable direction happens, something else automatically puts it back on course. Therefore, coordination is achieved not by an omniscient and rational agent, but by the self-correcting action of college departments (Birnbaum, 1989).

Birnbaum states that the models are helpful in explaining and analyzing systems, but it is not possible for any model to fully explain a system or structure, and it is not possible to determine a model as the best. While this statement points out that sticking to a single model when examining the governance of higher education institutions may limit the researcher, it indicates that a comprehensive framework should be created that interacts with other models while developing proposals for the organization. The important thing is to determine how the campus components interact with each other, because the loose or tight coupling of the interaction between these components provides the researchers with patterns that help to understand the organizational structure and culture (Birnbaum, 1988). In this context, the aim of this study is to examine the institutional governance models observed in higher education institutions in Turkey within the aforementioned framework. Accordingly, firstly, parameters belonging to each model were deduced and these parameters composed the sub-purposes of the study such as comparing universities based on foundation years, size and degrees, defining aims of the universities and analyzing organizational structure and functioning through organizational components and behaviours. 


\section{Method}

\subsection{Research Design}

The organization and functioning of higher education institutions are of critical importance in achieving the goals determined at the institutional and national level, as well as providing important clues about the institutional culture. In this study, it is examined how the institutional governance observed in the Turkish higher education system functions. Institutional governance is taken as a case and studied in depth within its context and limits. Therefore, Single case study (Yin, 2014) was determined as the research design to follow. Case studies also allow the theoretical analysis or explanation of the situation in question (Gilham, 2000). In this context, the governance case was evaluated in terms of the theoretical framework developed by Birnbaum. In this context, firstly, the research question was stated. Then, the case, which is the focus of the research, was defined. Lastly, the context in which the governance case in higher education institutions would be examined was determined.

\subsection{Study Group}

The study group consisted of 10 participants who were experts in the field of higher education. They were determined through theoretical sampling. Accordingly, while collecting and coding the data, new participants were asked to participate in the study (Glaser \& Strauss, 2017). All of the participants are currently working at national state or foundation universities or abroad. 5 of the participants are full professors, 4 of them are associate professors and 1 of them is assistant professor. 5 of the participants holds their associate professor title in educational sciences while 3 of them in the field of higher education studies. 3 of the participants are female while 7 of the participants are male.

\subsection{Data Collection}

Case studies require the use of different data sources. In the study, data were collected from three different sources, namely related literature, statistical data and interviews. While the relevant literature constitutes the theoretical framework of the study, various statistics about Turkish higher education institutions constitute a concrete data source for both a better understanding of the context and a comparison of institutions. Interviews to collect in-depth information were conducted in a semi-structured manner in order not to limit the answers of the participants. While developing the interview form, first of all, an item pool was created, expert opinion was obtained, and a pilot application was conducted. Ethics committee approval was obtained before data collection and a consent form was presented to the participants. The participants were also ensured about confidentiality and anonymity. Interviews were conducted online and each interview lasted for two hours approximately. The questions were formed based on premises and parameters suggested by Birnbaum for each model. Question examples from the interview form are as follows:

-What are the purposes of universities within Turkish higher education system?

-Could you elaborate on decision-making process in universities?

-Have you ever observed interest groups in higher education institutions? How would you describe them?

\subsection{Data Analysis}

After the interviews, the approval of the participants was obtained through member check and the analysis process started. Since the aim of the study is to assess the parameters suggested by the governance models, the data were analyzed in an analytical way to obtain the themes or patterns (Glesne, 2016). Accordingly, first of all, the content of all interviews was transferred to the software. Then, the data were coded and themes were obtained and analyzed according to the parameters of each model. Again, in accordance with the aim of the study, continuous comparisons were made and the codes under each theme were examined according to their similar 
and different aspects. In addition, the findings from the interviews were interpreted in a holistic perspective with the data obtained from other data sources mentioned above.

\subsection{Reliability and Validity}

Four basic conditions are mentioned for case studies: credibility, reliability, confirmation and being data sourced (Yin, 2014, as cited in Akar, 2016). In this context, more than one data source and theoretical framework were used to increase the structural validity of the study. Again, the participants of the study work in different higher education institutions in terms of both type and city/country, and they gave both comprehensive and comparative answers to the interview questions, taking into consideration of their own context. In addition, the theoretical framework and the findings were conveyed in a detailed and meaningful way to ensure the credibility or internal validity of the study. Findings from different data sources are presented with a holistic perspective. Again, the limitations of institutions or contexts where generalizations can be made to ensure transferability or external validity are also mentioned. In order to increase reliability, the findings obtained from different data sources were presented in a clear and understandable way, and member check was applied before the analysis of the data obtained from the interviews.

\section{Findings}

In this study, which examines the governance models observed in the Turkish higher education system, the data obtained through relevant literature and statistics (in 2021) and semi-structured interviews were analyzed in a holistic and complementary way. Variables such as the age of higher education institutions, the region they are located in, the number of students and teaching staff, and the degree and type of programs taught distinguish these institutions from each other in terms of purpose and functioning according to Birnbaum (1988). So, data analysis started with focusing on statistical data. Accordingly, there are 207 higher education institutions in Turkey, of which 129 are state universities, 74 are foundation universities and 4 are foundation vocational schools. When state and foundation universities are calculated together, Istanbul is the city that hosts the most universities. While 46 of the 52 universities in Istanbul are foundation universities, only 6 of them are state universities. When evaluated based on regions, Marmara and Central Anatolia Regions come first with 27 state universities, and when foundation universities are included in this number, Marmara Region is the region that hosts the most universities-72 universities.

Considering that the first higher education institution in Turkey was established in 1933, 206 new higher education institutions started to function in 88 years. Table 1 shows the ages of higher education institutions.

Table 1

Foundation Years of Universities in Turkey (adopted from Karada $\breve{g}, 2021$, p. 304)

\begin{tabular}{lcc}
\hline Year & State University & Foundation University \\
\hline $1933-1954$ & 3 & - \\
$1966-1974$ & 10 & - \\
$1975-1981$ & 6 & - \\
1982 & 8 & - \\
$1983-1991$ & 1 & 1 \\
1992 & 23 & 1 \\
$1993-2005$ & 2 & 22 \\
$2006-2009$ & 41 & 16 \\
$2010-2014$ & 10 & 17 \\
$2015-2017$ & 7 & 9 \\
$2018-2021$ & 18 & 8 \\
Toplam & 129 & 74 \\
\hline
\end{tabular}


Despite the number of higher education institutions, it is observed that the number of registered students is quite high. Table 2 shows the number of students by university type and degree level. Accordingly, the largest part of 7,241,403 students enrolled in associate degree, daytime and evening education, and open education and bachelor programs is composed of 4,494,451 students from 4-year-undergraduate programs.

Table 2

Number of Students by University Type and Level of Education (2019-2020)

\begin{tabular}{lccccc}
\hline University Type/Degree & Associate & Undergraduate & Master's & Doctorate & Total \\
\hline State U. & 2820052 & 4101153 & 229550 & 90648 & 7241403 \\
Foundation U. & 155651 & 393298 & 56084 & 10594 & 615627 \\
Total & 2975703 & 4494451 & 285634 & 101242 & 7857030 \\
\hline
\end{tabular}

The high number of students will bring along the need for academics. Although the academic ranks have changed over time, the current ones are Professor, Associate Professor and Assistant Professor. Table 3 summarizes the number of academics in Turkey by university type.

Table 3

Number of Academics by University Type

\begin{tabular}{lcccccc}
\hline $\begin{array}{l}\text { University } \\
\text { Type/Ranks }\end{array}$ & Professor & $\begin{array}{c}\text { Associate } \\
\text { Professor }\end{array}$ & $\begin{array}{c}\text { Assistant } \\
\text { Professor }\end{array}$ & Lecturer & $\begin{array}{c}\text { Research } \\
\text { Assistant }\end{array}$ & Total \\
\hline State U. & 25670 & 15580 & 32530 & 31069 & 46820 & 151669 \\
Foundation U. & 4753 & 2078 & 8735 & 7064 & 4737 & 27367 \\
Total & 30423 & 17658 & 41265 & 38133 & 51557 & 179036 \\
\hline
\end{tabular}

In higher education institutions in Turkey, degrees are offered in different types and levels, including associate/undergraduate, postgraduate (master's and doctorate) and proficiency in art. The number of associate and undergraduate programs in state and foundation higher education institutions is considerably higher than graduate programs. Table 4 summarizes degrees by university type.

Table 4

Number of Programs by University Type and Degrees

\begin{tabular}{|c|c|c|c|c|}
\hline $\begin{array}{l}\text { University Type/ } \\
\text { Degree }\end{array}$ & Associate/Undergraduate & Master's & Doctorate & Proficiency in Art \\
\hline State U. & 12717 & 10385 & 5011 & 126 \\
\hline Foundation U. & 7579 & 2511 & 545 & 15 \\
\hline Total & 20296 & 12896 & 5556 & 141 \\
\hline
\end{tabular}

When the above-mentioned statistical data on higher education institutions in Turkey are evaluated in general, one of the striking points is the high number of students. Especially with the increase observed in the number of universities after 2006, there has been a significant increase in the number of students. Since most of the students attend associate degree or undergraduate programs, it can be thought that general purpose of the education offered at universities is preparation for the profession. In addition, a significant proportional difference is observed when the numbers of students and academics are compared. Besides, most of the academics are assistant professors.

In order to examine functioning of higher education institutions in depth, the opinions of academics who are experts in the field of higher education were consulted. The themes presented below refer to components of organizational analysis, such as purposes, relations, culture, etc. Based on them, parameters of each model and interview questions were obtained and answers to interviews questions were discussed accordingly below. 


\subsection{Purposes of Universities}

When making an analysis of institutions, it is necessary to examine first of all how they pursue their goals and objectives. In this context, the participants were asked about the main objectives of the universities in the Turkish higher education system and how these objectives emerged. The answers given to this question are examined under the sub-themes; education, research and contribution to the society.

\subsubsection{Education}

In Turkey, there has been a significant increase in the number of higher education institutions and students accessing higher education, especially in recent years, with the approach of "university for every city". It is stated that especially newly established or "small" institutions have not completed their development or are in the process of forming their institutional identities. When the necessary infrastructure or funding is not provided, these institutions are transforming into an environment where university education is offered to students who graduate from high schools. According to this, examples of expressions related to the answers given by the participants on the theme of education are given below.

When we talk about the aims of the university, we are talking about the aims of Council of Higher Education [CHE]. ... In fact, the main purpose of most universities is teaching. It is also a question mark how well they do this, because there are serious problems with both the quality and the number of faculty members. In order to solve this, CHE started the concept of research universities, but even they still focus on teaching (P6).

Apart from what is determined by the law, the main purpose of universities in Turkey is to train students enrolled in the relevant departments in a way that will gain certain qualifications... University administrators may be more interested in the technical dimension of education and training activities in order to realize the qualifications in line with the relevant programs (P8).

In fact, the main purpose of Turkish universities is to keep the students who graduated from high school institutions in the system for 4 more years, to show the unemployment rates low (P4).

\subsubsection{Research}

Universities have existed for many years as centers where new knowledge is produced and presented. This situation is sometimes related to the solution of changing or emerging problems, and sometimes depending on the desire of academics to deepen in the field of interest. The fact that universities act in the context of certain missions and plan to realize this mission has emerged especially with the "Carneige Classification" and continues with the label of "Research Universities" in the Turkish higher education system. Participants state that although the main purpose of universities is to produce knowledge, even the research universities cannot fully fulfill this mission, especially due to the limited autonomy and lack of various infrastructure and support. However, it was emphasized that new knowledge was produced in order to increase the number of articles and individual development was more important than regional or national development. Examples of expressions related to this are given below.

Without considering too much its contribution to science, without considering too much its practical contributions for problem solving, we confront with increasing number of articles as scientific production. The majority of universities are busy with increasing the number of articles, projects and citations. Well, when these numbers increase, will scientific production, which is the real purpose of universities, be achieved or will we be realizing it? (P3).

If universities determine their own missions such as research and development and focus on graduate education, or if such autonomy is provided to them, we can say that scientific research in higher education is carried out for scientific purposes, otherwise it is no more than filling out a CV (P9). 


\subsubsection{Contribution to society}

Contribution to society has become a prominent goal in universities, especially in systems where financing is provided by public resources, and society's needs and expectations have greatly affected the functioning of universities. The participants also evaluated their contribution to society or their regional and national contributions at a low level for Turkish higher education institutions and stated that increasing cooperation with industry or other institutions created a competition between universities to make projects, and universities that could not achieve this put pressure on academics. Examples of expressions related to this are given below.

Contribution to society or research and development has gained importance especially in recent years, with the influence of YÖKAK, and universities and academics have begun to focus on this issue. This situation or the criteria for promotion or appointment also causes a pressure factor on academics (P6).

Recently, with the encouragement for cooperation, universities are expected to become institutions that serve society. If there is a problem in an area, the solution is expected from the university...(P9).

Considering the views of the participants in all three sub-themes, the expectations from universities in the Turkish higher education system are mainly to education, research and contribution to the society. The discussion of the mission of universities implies that universities cannot fulfill more than one purpose at the same time while a strategy that channels universities according to their own institutional infrastructure and experience must be developed. In this case, universities within the Turkish higher education system partially serve all purposes. Research university label is given to success rankings in certain fields by CHE. With this approach, 11 universities were determined and certain advantages were provided to these universities in terms of budget and human resources. However, as stated in the participant opinions above, since the aims and missions of universities are determined by CHE, all universities are treated "the same" and universities are increasingly similar to each other in terms of purpose and product. The determination of the objectives by the universities also makes the universities the institutions that seek their own special objectives. Therefore, it can be said that universities within the Turkish higher education system are still at the point of discovering their goals.

\subsection{Universities' Relations with the Environment}

Universities, as an educational institution, are structures that receive input from the environment and offer output to the environment. The input it receives from the environment and the output it presents to the environment also determine the relations of universities with the environment. Considering the relations of Turkish universities with the environment, it is observed that they have a different interaction environment than other public institutions and participants were asked to describe those relations. The participants stated that when examining the relations of universities with the environment, it is necessary to examine what they identify as the environment first:

First of all, it is necessary to examine what the university accepts as an environment. It is necessary to determine how universities define what their environment is... The administration develops a mechanism for whom it can respond, account, praise itself, and benefit from (P3).

The environment, as the structure that it will both affect and be affected by, is very important in determining the functioning and strategies of universities. In other words, the environment is the mechanism by which the university determines and regulates its input and output. However, the participants stated that Turkish higher education institutions are more introverted and closed institutions. Examples of expressions related to this are given below.

I do not think that the environment has a strong influence on the university administration. The functioning of the instutiton is mostly between state institutions, universities take decisions and send them to the CHE. That's why environmental actors, let's say a municipality or an NGO, have no effect on the university. This inevitably makes universities semi-closed. The main reason for this is that the influence of the state is too much in higher education institutions (P1). 
There is a more introverted structure in universities in Turkey, this situation has been tried to be changed with processes such as quality accreditation, but it is still the same. Again, the nonparticipation of external stakeholders in the elections in universities creates a closed system...(P2).

When the participants' views are evaluated together, it can be said that Turkish universities are institutions that show semi-open system characteristics. Although industrial collaborations or initiatives that will accelerate social development are encouraged, as mentioned above, if these goals are not adopted by university members, interaction with the environment may be limited or may not occur at the expected level. However, it can be thought that the environment is a pressure factor on the university and this situation forces universities to create a functioning or defense mechanism.

\subsection{Providing Services and Offering Products in Universities}

Universities are expected to offer many different products. The emergence and presentation of these products also requires the use of many services, infrastructures or technologies. This situation makes the functioning of universities more fluid, as it also leads to uncertainty in the provision of services and the use of technology. Participants stated that expectations from universities are too high, but universities are insufficient to meet them for various reasons. However, they also stated that as in scientific research and scientific production, product and service diversity require autonomy, budget and support. Examples of expressions related to this are given below.

This is a little bit about academic freedom or autonomy. If you provide this authority to departments or divisions and allow them to establish their own research programs, their own research funds and their own research laboratories, it will be possible to present various products at universities (P3).

There is a debate on this subject, should we expect this variety of services from a single university or should we distribute it to universities? This is about the mission discussion (P2).

It was emphasized in the opinions of the participants that the expectations from the universities in relation to the objectives of the universities and therefore the missions attributed to them were too high, but that the universities were insufficient in providing services. However, inadequacy of infrastructure or lack of support makes universities try to maintain their functioning with current facilities. Dependency on public resources and partial autonomy prevent universities from determining their own products and outputs.

\subsection{Motivation and Professional Development}

As mentioned before, the expectations of states, societies and individuals from universities are quite high and varied. In particular, academics need to constantly develop themselves and adapt to changes in order to respond to these expectations. In this context, the participants were asked how universities or university administrations motivate employees to achieve their goals and how they contribute to their professional and personal development. Almost all of the participants stated that higher education institutions are insufficient in providing motivation and that they do not contribute enough to the professional and personal development of the personnel. Examples of expressions related to this are given below.

Again, in order to fulfill the criteria determined by the CHE, universities started to focus on trainings that would contribute to the personal and professional development of academics. While there is still a lack of infrastructure or the number of courses is so high, the motivation is not very high (P6).

Generally speaking, there isn't really much motivation. The support mechanisms provided to academicians by the administration are very limited. It is almost non-existent, especially in public universities (P1).

When the views of the participants are evaluated together, it is emphasized that higher education institutions are insufficient to provide motivation and personal and professional development opportunities, and it is understood that this situation is closely related to the university administration. While managers who care about the development of their personnel 
should provide the necessary infrastructure and incentives, it can be said that motivation and development is regarded as an individual attepmt in universities. In addition, it is understood from the participants' opinions that the participation of the stakeholders in the decision making will increase motivation to realize the decision.

\subsection{Decision Making at Universities}

Decision-making is a very important process in universities, as in many organizations, and it also provides important information about functioning and culture of the organization. At the same time, it is closely related to the management approach or capacities of the managers. In this context, the question of how the decisions are made in the universities was asked to the participants and they were asked to explain the process. Most of the participants stated that decision making in universities is not fully realized and the decisions are usually referred from the higher boards. Examples of expressions related to this are given below.

In Turkey, the system does not force university higher management to make rational decisions, on the contrary, there is a system that is suitable for direct decision making or top-down decision making (P2).

There are certain points where universities can make decisions, hiring staff, distributing courses and investigations. There may be practical decisions, for example, how the lessons will be held during the pandemic period. The decision template is the same everywhere, the details are different from each other... (P3).

When the opinions expressed by the participants on the decision-making processes are considered together, it is difficult to say that universities have a clear decision-making mechanism. In addition, the approach of the managers to the decision-making processes greatly affects the decision-making processes. While a clear decision-making strategy did not emerge, the participants made detailed explanations about how the decisions were not made. While this situation reveals a structure that can be called complex or chaotic in university administration, it also points to the decision-making uncertainty or the garbage can decision-making model, which can be explained as the choice of the most compatible among the existing decisions. Accordingly, decisions are made not for the solution of this problem, but because it has to be done, and the participation of the stakeholders in the decision is discontinuous and variable.

\subsection{Communication, Integration and Cooperation in Universities}

Due to the nature of educational institutions, they are expected to be institutions where communication, interaction and cooperation are intense. In this context, questions about how communication, integration and cooperation processes are carried out at universities were asked to the participants. Participants stated that communication and cooperation between stakeholders and academics in particular is limited in addition to management levels. The participants, who stated that communication takes place vertically from top to bottom, also stated that understanding of cooperation between departments or divisions has not developed, and that the integration is tight and loose from time to time. Examples of expressions related to this are given below.

Communication is usually carried out through official channels (P5).

It should be noted that there is almost no cooperation between academics in Turkey...Science does not exist without cooperation. As such, there is only one subject that academics know, and they have been working on this subject for 30 years (P3).

The purpose of the faculty or department does not concern the academics, those who are closely related come together and do similar works, apart from that, there is complete individuality (P10).

When the answers given to this question are considered together, it was stated by all the participants that communication and interaction in universities is limited. Communication mostly takes place vertically; horizontal or circular communication is not observed frequently. As a result, there is a loose coupling between units and departments. Cooperation or acting together to achieve 
common institutional goals is weak, and individuality and realization of individual goals are at the forefront. However, some participants talked about the tight coupling between higher management boards and employees.

\subsection{Control and Feedback in Universities}

Control and feedback mechanisms, especially testing the effectiveness of the decisions made, are an important self-assessment tool in higher education institutions. Based on the results of this assessment, strengths or weaknesses are identified and improvement actions are taken. In this context, the participants were asked how control and feedback mechanisms work in universities. They stated that in most cases, control or feedback is not needed or an action plan for results is not developed. Examples of expressions related to this are given below.

In my opinion, there is no functioning control mechanism in public universities. For example, a strategic plan is made every term and it should be checked whether there is an improvement or increase according to this plan, but we do not control, everything is only on paper... Maybe we can count YÖKAK as a control mechanism (P1).

This control or feedback has increased lately, especially in quality assurance systems, with pressure for accreditation. But here, too, it is necessary to ask, what will happen if universities do not provide them? ... The state university is established and financed by the state. Will the state shut these institutions down when they cannot provide quality assurance or accreditation? (P9).

Mechanisms such as control, supervision and feedback play a very important role for organizations to survive. When considering the universities within the Turkish higher education system, the participants stated that these mechanisms are not operated effectively and even if they are operated, no action is taken according to the results. In addition, processes such as quality assurance and accreditation are also considered as external control mechanisms for universities. However, the fact that the feedback is not processed does not take these processes beyond filling out official forms.

\subsection{Power and Authority in Universities}

The participants were asked to define the elements of power and authority in higher education institutions, which points out cricital aspects of organizational functioning. Examples of expressions related to this are given below.

I have a thought on this subject, does being a very good doctor or seeing patients for a long time make someone a good rector? Look at the universities that have medical faculties, almost all of them are medical professionals. This raises the question of how rectors are determined. Here, I see department heads as an important power figure... (P4).

Power, how we define power, the potential to influence someone. To impress someone, you need to have something to impress, knowledge, merit, charisma, experience, we can count more than that. Now, if you ask me whether the power of the rectors stems from these, I would say no... Therefore, the management can only use the power of being appointed over the employees, use its legal authority (P9).

Power sources can be listed as legal, charismatic, knowledge and expertise. Almost all of the participants define the source of power or authority in universities as legal power or the power of being appointed. In this case, it can be thought that the power of the appointed rector comes from the appointing authority with the abolition of the rectorate elections.

\subsection{Institutional Culture in Universities}

Organizational culture is again an important structure in the functioning of institutions. Organizational culture, norms, values and history of the organization can be influential at many stages from mission setting to implementation processes. In this context, the participants were asked to describe the organizational cultures they observed at the universities and were asked whether there was a similarity between the cultures of the universities. Examples of expressions related to this are given below. 
In the past, there was an ecole, especially in rooted universities, and within the framework of this ecole, teachers trained their students within a master-apprentice relationship. There were customs and traditions rather than written rules. This academic culture or wisdom is gone. We assimilated. In fact, this situation causes the same kind of homogeneous deterioration in universities (P6).

[...] In Turkey, for example, when university is mentioned, there are some slogans that are memorized. Similar presuppositions have become the norm, and all universities are doing the same to comply with this norm. (P3).

There are too many imitation processes among universities (P4).

On organizational culture in universities, participants first stated that each institution has its own unique culture, but especially recently, these cultures are being similar to each other. The reasons such as the management of all universities, regardless of state or foundation, depending on the same legal processes, the increase in the number of administrators appointed from outside the institution and not familiar with the organizational culture, the difficulty in obtaining external financing and funding, and the increase in the expectations of demand groups called the scientific "market" have hindered the emergence of a distinctive culture in universities. It also causes the existing settled cultures to weaken.

\subsection{Change in Universities}

It can be said that change is inevitable especially for educational institutions. So, participants were asked how they define change in universities and the source of change. Examples of expressions related to this are given below.

Change usually takes place in two ways, either top-down or bottom-up. In Turkey, it usually takes place from top to bottom, even if a change is requested at the level of the department, it stays there, it is not expanded to the general functioning (P5).

The aims of the CHE and therefore of the state are very effective in the functioning of universities. If there is a change in them or with the changes in political, economic or social status, the higher boards force the universities to change or expect a change in production (P9).

In the statements of the participants about change, it can be concluded that there are top-down and forced changes in universities, which comes from the CHE mostly and deeply affects the functioning of the universities. However, lack of participation of internal stakeholders indicate that there may be problems in the adoption and implementation of change, while implying stagnation in universities.

\subsection{Interest Groups}

According to Clark (1983), anyone talking about academic organizations is likewise talking about interest groups. In other words, visible or invisible cliques in universities create pressure on the university and its functioning with the effect of the power that brings them together. These cliques or interest groups, which can come together with scientific, sociological, economic, political and many other motivations, can be a guide for university administrations at certain stages. In this context, the participants were asked about power groups or cliques, how they came together and the pressure they exerted on the university. Examples of expressions related to this are given below.

For example, if a building is to be built, which faculty has more or dominant teachers, their needs are met first. We can talk about dominant cliques (P3).

Universities are the places where such groups are observed a lot, a few people come together around a certain power or common denominator to form a clique. Research funds or research centers actually constitute a pressure group. Which projects will be funded inevitably determine the subjects of further research, and research on similar subjects is either done or not (P4).

Almost all of the participants stated on interest groups or cliques that they are frequently observed in universities in different forms. These groups, which come together with various common denominators, may cause pressure not only on management levels but also on all 
university stakeholders. On the other hand, the fact that people supported by these cliques come to the administrative levels raises questions about the informal or implicit functioning of universities. However, research funds or research centers also constitute a scientific interest group. Funding or support is an important determinant in research, so academics need support to carry out their scientific work. In a way, the field and subject of future projects are determined in advance, and scientific freedom is restricted.

\subsection{Administrative Structure and Rectorship in Universities}

Finally, questions about the administrative structure and rector's office in universities were asked to the participants and they were asked to give information about the administrative processes. Firstly, examples of statements regarding the management structure are given below.

No matter how much they want, the rectors cannot go beyond the legal limits, they cannot choose their own human resources, the students enroll as a result of exams anyway. When we consider all these, there is a daily operation, there is a standardized operation... (P1).

...While raising them, the system creates a sieve, whatever mechanism exists, people similar to themselves are definitely selected, as the number of administrators with this tendency increases, universities are similar to each other, everyone finds people who are similar to each other. In some way, incompetence and disqualification work like a magnet in universities (P10).

Accordingly, it can be said that most of the time, a rational or strategic management approach is not adopted in universities, and people who have the same values or have the same views come together at the management levels. In addition, it can be said that there is learned helplessness in universities. In particular, the appointment of rectors and other administrators may oblige individuals to implement some decisions even if they do not adopt them, in this case, since reacting to administrators will be seen as indirectly reacting to higher boards and appointing authorities, many tasks are fulfilled on a daily basis, as is stated in the statements of the participants.

Examples of statements regarding the rector's office, the roles and powers of the rector are given below.

If the rectors did not have such broad powers, we would not have these discussions today (P4).

Every rector uses political tactics because there are too many pressure groups or cliques around him. While trying to balance these, the rector sometimes makes tactical choices; whom to assign to which task or whom to appoint (P3).

...the rectorate is actually a very difficult job in Turkey. He has to balance and deal with everything... You have to balance the internal interest groups and the external pressures, so... your whole job is to balance the pressure placed on you (P1).

Almost all of the participants regarding the duties and responsibilities of the rectors used the expressions "broad powers" or "all-powerful". Besides, a few participants used the term "top manager" for the rector. These expressions suggest an implicit monarchy within the university. When the rector changes, another rector "similar to him" will be determined, as is also mentioned in the participants' statements. This indicates that although the mission statements, aims or products of the universities within the Turkish higher education system have changed or updated, they still resemble a medieval institution in terms of functioning. However, one of the important responsibilities of rectors is to balance the pressure created by interest groups. It can be stated that one of the most frequently used tactics by the rectors are bargaining and bartering.

\section{Discussion and Conclusion}

The main purpose of this study is to analyze organizational functioning of universities within Turkish higher education system in terms of Birnbaum's five models of organizational governance. To do so, first, theoretical framework of the study was composed and parameters were obtained based on each model. In addition to theoretical framework, findings from statistical data and interviews were analyzed together to compare with parameters. Lastly, parameters observed 
frequently were matched with the models and governance of higher education institutions were evaluated in this part.

Birnbaum mentions the demographic characteristics of the university for each model in the governance framework he constructed. Therefore, considering the data on universities first, there are 207 higher education institutions in Turkey, including 129 state, 74 foundation, and 4 foundation vocational schools since 1933. While the number of state universities established until 2006 was 53, only 41 new state universities were established between 2006-2009. Again, while the number of foundation universities established before 2006 was 24, this number increased to 74 with 50 new universities established after 2006. This indicates that most of the universities in Turkey are relatively new universities. The average number of academics per institution is 865 . While the most crowded group is composed of research assistants, it is followed by assistant professors and lecturers. Again, the number of students per institution is 18,470 and most of them are undergarduate students. In this case, the average number of students and academic staff in a higher education institution is 19,335 , which is a very high rate. Therefore, it can be claimed that higher education institutions in Turkey are quite crowded in terms of their current size. These factors lead to several problems such as administration, finance, human resource and local interference (Özoğlu et al., 2016). Therefore, it could be deduced that these "new" universities might still be trying to establish their own way to function.

When the five-model governance framework is evaluated in terms of the above-mentioned characteristics of universities, it has been revealed that universities in Turkey are most compatible with the organized anarchy model in terms of the number of students and faculty members. Typical institutions in which the political model is observed also have high student numbers and both undergraduate and graduate programs, but it can be argued that they are smaller organizations than anarchic ones as Birnbaum (1988) suggested. When the universities are evaluated in terms of their establishment years, the organizations in which the collegial model are expected to have a long history and a very old culture and tradition. The increase in the number of universities established in Turkey, especially since 2006, suggests that these institutions are still in the process of being established and that the shared values and beliefs required by the professional model have not yet been formed (Lee, 2007).

When it comes to discuss findings of the interviews with experts working in the fields of higher education and higher education management, the participants were first asked about the aims of universities within the Turkish higher education system. In line with the literature in the field of higher education, education, research and contribution to society are the main objectives of universities (Baldridge et al., 1977). These are followed by regional development due to the differentiation of mission and thematic university concepts that have been emphasized recently (Frondizi et al, 2019). Participants stated that almost all universities function for educational purposes and that other purposes are often imitated purposes in mission statements. One of the most current debates about the aims of universities is that these are determined by the Higher Education Law, so even if universities set their own specific goals, they are actually trying to realize the goals of the state. When this situation is evaluated in terms of governance models, it is compatible with the bureaucratic model and the anarchy model. While the set of rules and practices that are standardized within a certain program to achieve legal goals (Blau, 1994; Stroup, 1966) resembles the bureaucratic model, it is open to debate whether the rationality of these goals or the rational behavior of the personnel providing services to achieve them. The uncertainty of the goals at the organizational level and the lack of knowing which service or technology should be used (Weick, 1976), again indicates the anarchy model.

The participants were asked to describe the institutional environments of the universities which provide resources and ensure legitimacy, and the answers indicated that the universities adopted the existing or known environments rather than determining a new environment. Accordingly, the fact that the state itself is the resource provider for state universities makes these institutions completely dependent and accountable to the state, and in addition, if universities fulfill its 
objectives, their institutional legitimacy will be recognized by both the state and other organizations (Tolbert, 1985). In addition, participants stated that some universities are quite closed structures, while others stated that industry or regional development cooperation creates an environment for the university. The fact that the university and its environment mutually affect each other also shows that the environment can be a factor of pressure. This situation is especially criticized for the fact that research institutions and funds are the driving force that directs scientific research (Auranen \& Nieminen, 2010; Leifner, 2003). The fact that research programs are determined by higher institutions or research centers, not by academicians or universities, and the funds are donated according to these programs is actually a situation that harms scientific autonomy (Resnik, 2008). For this reason, resource dependency is frequently discussed for universities and it is recommended that universities turn to external resources and ensure the balance between them (Tolbert, 1985). In addition, the areas that universities determine as their environment are expected to have an impact on the functioning of universities, which increases the expectation of service or product diversity according to the determined environment. However, since the environment of universities is limited and similar, the variety of services or products is also low. Thus, bureucratic model matches with this situation as institutional environments of the universities are quite similar to each other and they tend to produce standardized outcomes.

How the decision-making processes are carried out is an important clue for analyzing organizational behavior in universities. Findings related to this revealed that the decisions were "not taken" and "reported" by the higher boards. In other words, universities are the implementers of the decisions of the higher committees. It has been concluded that many universities imitate themselves or each other in this regard, instead of taking risks and renewing, maintaining the functioning system or adopting practices that other universities have tried and obtained positive results increases the similarity between universities and makes decision-making a routine paperwork carried out when the time comes, which turns it into a ritual (Meyer \& Rowan, 1977). Although the routine or excessive dependence on the legislation evokes the bureaucratic model, not operating the rational decision-making process, which requires the determination of the problem, collecting information, selecting possible solution proposals, testing them, and finally continuing with the effective one (Scott, 2003), but limited rationality may be possible within organizational or environmental constraints (Daft, 2010). In situations where the choice or decision-making process is generally problematic, uncertainty is high, and participation is unclear, managers have decisions that they make when the time comes, from a "garbage can" where problems, solutions and choice opportunities are intertwined instead of following a system or sequence (Cohen et al., 1972). Universities are focused on solution rather than a systematic decision-making process. They try to solve the problem by selecting the appropriate solution from the available solutions. It is possible to talk about a chaotic structure of decision making in universities and this situation is compatible with garbage can decision-making, and therefore, organized anarchy model.

Communication, integration and cooperation are very important in the realization of organizational goals. Educational institutions are also institutions where communication and interaction are frequently experienced, and cooperation between stakeholders is an indicator of the adoption of decisions. In this context, how the mentioned processes take place in universities has been examined. While the findings indicate that horizontal communication and cooperation between stakeholders in universities is quite limited, there is low integration or loose coupling between units and even individuals. Therefore, individuals try to achieve their own goals rather than the goals of the university. The participants, who interpreted the lack of cooperation between academicians as a hindrance in terms of scientific production, stated that the knowledge produced was often limited and repetitive. Taken together with the aforementioned garbage can decisionmaking process, uncertain technology and fluid participation (March \& Olsen, 1975) also support this situation. 
Findings on the control and feedback processes employed in universities show that these processes are not carried out in accordance with their purpose and are handled as paperwork. The fact that there is no regulation or sanction regarding the results of the evaluations makes them dysfunctional. The participants, who stated that the most important source of feedback in universities was academics, also stated that they were often unresponsive due to cultural codes or low power of influence. The cybernetic model, which is one of the five governance models, includes structures and processes from the other four models and requires a system that constantly regulates itself based on feedback (Birnbaum, 1989). In this case, it can be considered that the cybernetic model is not observed frequently in universities in Turkey, and it is not a common to take into consideration opinions of each stakeholder, which is one of the assumptions of the collegial model.

While organizational culture gives important information about the identity of the institutions, it often includes behavioral patterns for functioning. The findings about the culture observed in universities, the level of adoption of culture and the formation of a homogeneous culture among universities show that organizational culture is unique for each university by nature, but due to the same laws and regulations, the cultures are resembling each other and similar administrative processes are experienced in universities. While the values and practices that make up the culture are still effective, especially in universities that can be called "rooted" and where the informal structure is stronger, it is noteworthy that imitation processes are experienced a lot especially in organizations that are "new" or "small" (DiMaggio \& Powell, 1983). Şenses (2007) states that universities, which can be considered new in terms of establishment, were founded based on the "core" of the older higher education institutions and that they were far from the understanding of "innovation" at the very beginning because the managers of the older institutions served as their founders. So, newly established universities carry out processes similar to other universities in an effort to gain legitimacy or recognition but this prevents the formation of a culture that is unique and self-directed. Birnbaum (1988), who suggests that culture has a very important function especially in the collegial model, states that university stakeholders also form a family-like structure in which they are closely connected to their culture. In addition to culture, it is stated that the change process observed in universities is not institutional or culture-centered, but stems from senior management, just like decisions. Accordingly, a change in the legal aims and duties of universities will initiate a compulsory change process in all universities. Like organizational culture, stakeholders of higher education institutions will be exposed to change rather than adopting them.

When the management process in universities is examined in the context of power and authority, important findings about the academic existence of universities are obtained. Since universities are seen as science centers, it is expected that their administrators should have the competence and qualifications to be responsible for this science center. In this context, first of all, the source of power in universities was examined. The main sources of power are the position, personal characteristics, competence or expertise in a certain field, providing information and controlling (Robbins \& Judge, 2013). Karadağ's study (2021), focusing rectors' academic qualifications by examining the article, citation and $\mathrm{H}$-index scores, found that many of the current rectors do not have high citation numbers and the rankings of the universities where the rectors with high academic qualifications work are better. In this case, it is clear that especially the rectors of state universities are not appointed according to their academic qualifications or expertise. In the bureaucratic model, the rector is determined by appointment, in this way, it will be ensured that the rector is a competent person with high representative power. This is coherent with appointment system but it is not coherent with qualification assumption.

The findings of the study, on the other hand, point out that the power sources of university administrators in Turkey are often the legal power they transfer from the appointer. How rectors hold office in Turkey has been constantly changing since 1933. As rectorate elections lead to problems such as polarization and nepotism (Kurt et al., 2017) and that the best is not always 
chosen in the elections, and incompetent people may also be appointed (Rosovsky, 2017), there are some alternatives to elections such as board of trustees (Kavili Arap, 2011; Kurt, 2015; Kurt et al., 2017) and selection committee (Günay \& Kılıç, 2011). Findings indicate that the power "attributed" to the rector should be discussed before because the starting point of these discussions is that the power of the rectors is more than the university administrative boards and the senate. The legal and administrative power of being appointed by the President provides to the rector is evident, but the extent to which this power can be used is closely related to the rector's perspective or academic notion. If the rectorate is seen only as a management authority, a system that operates independently of the people will be established automatically, so that the rectors or names will change, but the system or institutional culture will continue to function in the same way. So, these findings are consistent with the previous findings on power and authority in terms of governance models.

The existence of cliques or interest groups as an effective pressure factor in the management and functioning of universities is clearly seen in the findings of the study. Accordingly, the fact that groups that have come together on the basis of certain ideology, common direction or interest in some cases provide them enough power to affect the decisions of senior management and this legitimizes their existence. That research centers or funds support certain research programs and enable researchers to carry out studies in certain fields makes these institutions another center of interest, similarly, industry or technology collaborations can be evaluated within this scope (Tandberg, 2010a, 2010b). The findings of the study revealed that these interest groups can be effective to a considerable extent and the rector tries to maintain a balance by making use of tactics such as bargaining, barter and reconciliation for these groups. This situation is closely related to the political model. Birnbaum (1988) uses the kaleidoscope metaphor when talking about the political model. Just as the kaleidoscope presents a different mosaic each time, various groups form a mosaic in universities that adopt the political model, and the rector has to manage this mosaic like a politician.

Universities have a very systematic and thoughtful structure within themselves. Erdoğan (2014) defines the Ministry of National Education as a system "structured almost like a state" based on the separation of powers -legislative, executive and judicial- and directed by the Minister of National Education. When this situation is applied to universities, it is seen that under the administration of the Rector with the senate (legislative), administrative boards (executive) and auditing processes (judiciary) and universities operate "like the state" based on the principle of separation of powers. However, the findings of the study revealed that a purposeful or rational management approach is not maintained in universities, and duties are routinely fulfilled.

Studies on the governance models observed in universities have revealed that there is no dominant governance model in universities in Turkey, and models that are compatible with each other are adopted (Aypay, 2006). However, it has been determined that the collegial model is observed more frequently in bureaucratic and older universities, especially in newly established universities (Karataş Acer, 2015). In a study on the governance models observed in education faculties, it was revealed that the political model was the most frequently observed model and the founding years of the universities created a significant difference between the observed models (Aypay \& Bektaş, 2010). This is in line with the suggestion that, as Birnbaum mentioned, these governance models are not intended to evaluate universities as good or bad, but rather provide a framework for better analyzing organizational behavior. The findings of this study, in line with previous studies, revealed that the reflections of the bureaucratic and political model are frequently observed especially in newly established universities, while the symbolic or collegial model is observed in older or traditional universities. In addition to these, the use of the organized anarchy model as a result of the chaotic structure that occurs with the growing structure and increasing presence of universities and the frequent use of the garbage can model in the decisionmaking processes are among the results of this study. What is crucial that all the governance literature suggest is to ensure autonomy for universities to discover their potentials and function 
accordingly. Also, academic culture in universities should be maintained as it is rather imitating from other ones, and, thus universities will have produced their own way of functioning.

Acknowledgements. This study is a part of $\mathrm{PhD}$ dissertation titled "Higher education governance in Turkey: Historical transformation, system coordination and institutional governance" of the first author under the supervision of the second author.

\section{References}

Allison, G. (1971). Essence of decision. Little Brown.

Akar, H. (2016). Durum çalışması [Case study]. In A. Saban \& A. Ersoy (Eds.), Eğitimde nitel araştırma desenleri [Qualitative research design] (pp. 113-149). An1.

Auranen, O., \& Nieminen, M. (2010). University research funding and publication performance-An international comparison. Research Policy, 39(6), 822-834. https://doi.org/10.1016/j.respol.2010.03.003

Aypay, A. (2001). Örgütsel analizde teorik gelişmeler: Yeni kurumsalcilık [Theoretical developments in organizational analysis: New institutionalizm]. Educational Administration: Theory and Practice, 28(28), 501511.

Aypay, A. (2006). The relationship between academic activities and organizational behavior at universities in Turkey. Educational Administration: Theory and Practice, 46(46), 175-198.

Aypay, A., \& Bektaş, F. (2010). Organizational models observed in faculties of education: A descriptive study based on the sample of instructors. Inonu University Journal of the Faculty of Education, 11(3), 45-59.

Baldridge, J. V., Curtis, D. V., Ecker, G., \& Riley, G. L. (1977). Diversity in higher education: Professional autonomy. Journal of Higher Education, 48(4), 367-388. https:/ / doi.org/10.1080/00221546.1977.11776557

Becher, T., \& Kogan, M. (1992). Process and structure in higher education. Routledge.

Birnbaum, R. (1988). How colleges work: The cybernetics of academic organization and leadership. Jossey-Bass.

Birnbaum, R. (1989). The cybernetic institution: Toward an integration of governance theories. Higher Education, 18(2), 239-253. https:// doi.org/10.1007/BF00139183

Blau, P. M. (1994). The organization of academic work. New York: Transaction Publishers.

Brennan, J., \& Teichler, U. (2008). The future of higher education and of higher education research. Higher education, 56(3), 259-264. https://doi.org/10.1007/s10734-008-9124-6

Capano, G. (2011). Government continues to do its job. A comparative study of governance shifts in the higher education sector. Public Administration, 89(4), 1622-1642. https://doi.org/10.1111/j.14679299.2011.01936.x

Clark, B. R. (1983). The higher education system: Academic organization in cross-national perspective. University of California Press.

Cohen, M. D., \& March, J. G. (1974) Leadership and ambiguity: The American College President. McGraw-Hill.

Cohen, M. D., March, J. G., \& Olsen, J. P. (1972). A garbage can model of organizational choice. Administrative Science Quarterly, 17(1), 1-25. https:// doi.org/10.2307/2392088

Daft, R. L. (2010). Understanding the theory and design of organizations (10th ed.). South-Western CENGAGE Learning.

DiMaggio, P. J., \& Powell, W. W. (1983). The iron cage revisited: Institutional isomorphism and collective rationality in organizational fields. American Sociological Review, 48(2), 147-160. https:/ / doi.org/10.2307/2095101

Erdoğan, İ. (2014). The transformation of Ministry of National Education system from separation of powers to unity of powers. Journal of Educational Sciences Research, 4(2), 329-340.

Frondizi, R., Fantauzzi, C., Colasanti, N., \& Fiorani, G. (2019). The evaluation of universities' third mission and intellectual capital: Theoretical analysis and application to Italy. Sustainability 11(12), 3455. https://doi.org/10.3390/su11123455

Gillham, B. (2000). Case study research methods. Continioum House.

Glaser, B. G., \& Strauss, A. L. (2017). Discovery of grounded theory: Strategies for qualitative research. Routledge.

Glesne, C. (2016). Becoming qualitative researchers: An introduction. New Jersey.

Günay, D., \& Kılıç, M. (2011). Election and appointment of a Rector in the Republican era of Turkish Higher Education. Journal of Higher Education, 1(1), 34-44.

Karadağ, E. (2021). Academic (dis) qualifications of Turkish rectors: Their career paths, H-index, and the number of articles and citations. Higher Education, 81, 301-323. https://doi.org/10.1007/s10734-020$00542-1$ 
Karataş Acer, E. (2015). An analyis of the expansion of higher education in Turkey by using new institutional theory [Unpublished Doctoral Dissertation]. Gazi University, Educational Sciences Institute, Ankara.

Kavili Arap, S. (2011). The discussion of the procedure for the designation of rectors and the board of trustees in Turkey. Journal of Memleket Politics \& Administration, 6(16), 1-32.

Kerr, C. (1982). The uses of the university two decades later: Postscript 1982. Change: The Magazine of Higher Learning, 14(7), 23-31. https:// doi.org/10.1080/00091383.1982.9937006

Kurt, T., Gür, B. S., \& Çelik, Z. (2017). Necessity for reforming Turkish higher education system and possibility of governance of state universities by the board of trustees. Education and Science, 42(189), 4971. https:// doi.org/10.15390/EB.2017.6253

Lee, J. J. (2007). The shaping of the departmental culture: Measuring the relative influences of the institution and discipline. Journal of Higher Education Policy and Management, 29(1), 41-55. https://doi.org/10.1080/13600800601175771

Liefner, I. (2003). Funding, resource allocation, and performance in higher education systems. Higher Education, 46(4), 469-489. https://doi.org/10.1023/ A:1027381906977

March, J. G., \& Olsen, J. P. (1975). The uncertainty of the past: Organizational learning under ambiguity. European Journal of Political Research, 3(2), 147-171. https:// doi.org/10.1111/j.1475-6765.1975.tb00521.x

March, J. G., \& Olsen, J. P. (1989). Rediscovering institutions: The organizational basis of politics. Free Press.

Meyer, J. W., \& Brown, M. C. (1977). The process of bureucratization. The American Journal of Sociology, 83(2), 364-385. https://doi.org/10.1086/226551

Meyer, J. W., \& Rowan, B. (1977). Institutionalized organizations: Formal structure as myth and ceremony. American Journal of Sociology, 83(2), 340-363. https:// doi.org/10.1086/226550

Meyer, H. D., \& Rowan, B. (2006). Institutional analysis and the study of education. In H. D. Meyer \& B. Rowan (Eds), The new institutionalism in education (pp. 1-15). State University of New York.

Özoğlu, M., Gür, B. \& Gümüs, S. (2016). Rapid expansion of higher education in Turkey: The challenge of recently established public universities (2006-2013). Higher Education Policy, 29(1), 21-39. https://doi.org/10.1057/hep.2015.7

Resnik, D. B. (2008). Scientific autonomy and public oversight. Episteme, 5(2), 220-238. https://doi.org/10.3366/E1742360008000336

Robbins, S. P., \& Judge, T. A. (2013). Organizational behavior. Pearson Education.

Rosovsky, H. (2017). The university: An owner's manual (S. Ersoy, Trans.). Say.

Scott, W. R. (1981). Developments in organization theory, 1960-1980. American Behavioral Scientist, 24(3), 407422. https:// doi.org/10.1177/000276428102400306

Scott, W. R. (2001). Institutions and organizations. Sage Publications.

Scott, W. R. (2003). Organizations: Rational, natural, and open systems. Pearson Education.

Stroup, H. H. (1966). Bureaucracy in higher education. Free Press.

Şenses, F. (2007). The Turkish higher education system in light of international developments: Main trends, issues, contradictions and recommendations. Economic Research Center Working Papers in Economics, 7(5), 132.

Tandberg, D. A. (2010a). Politics, interest groups and state funding of public higher education. Research in Higher Education, 51(5), 416-450. https://doi.org/10.1007/s11162-010-9164-5

Tandberg, D. A. (2010b). Interest groups and governmental institutions: The politics of state funding of public higher education. Educational Policy, 24(5), 735-778. https://doi.org/10.1177/0895904809339163

Tolbert, P. S. (1985). Institutional environments and resource dependence: Sources of administrative structure in institutions of higher education. Administrative Science Quarterly, 30(1), 1-13. https://doi.org/10.2307/2392808

Vallée, R. (2003). Cybernetics and systems, from past to future. Kybernetes, 32(5-6), 853-857. https://doi.org/10.1108/03684920210443923

Weick, K. (1976). Educational organizations as loosely coupled systems. Administrative Science Quarterly, 21(1), 1-19. https:// doi.org/10.2307/2391875

Yin, R. K. (2014). Case study research: Designs and methods. Sage.

Zgaga, P. (2006). Reconsidering higher education governance. J. Köhler \& J. Huber (Eds), In Higher education governance between democratic culture, academic aspitations and market forces (pp. 35-50). Council of Europe Publishing. 